IZA DP No. 10121

Temporary Jobs and the Severity of Workplace Accidents

Matteo Picchio

Jan C. van Ours

August 2016

Forschungsinstitut zur Zukunft der Arbeit Institute for the Study of Labor 


\title{
Temporary Jobs and the Severity of Workplace Accidents
}

\author{
Matteo Picchio \\ Marche Polytechnic University, CentER, Tilburg University, \\ Sherppa, Ghent University and IZA \\ Jan C. van Ours \\ CentER, Tilburg University, \\ University of Melbourne, CEPR, CESifo, CREAM and IZA
}
Discussion Paper No. 10121
August 2016

\author{
IZA
}
P.O. Box 7240
53072 Bonn
Germany

\author{
Phone: +49-228-3894-0 \\ Fax: +49-228-3894-180 \\ E-mail: iza@iza.org
}

\begin{abstract}
Any opinions expressed here are those of the author(s) and not those of IZA. Research published in this series may include views on policy, but the institute itself takes no institutional policy positions. The IZA research network is committed to the IZA Guiding Principles of Research Integrity.

The Institute for the Study of Labor (IZA) in Bonn is a local and virtual international research center and a place of communication between science, politics and business. IZA is an independent nonprofit organization supported by Deutsche Post Foundation. The center is associated with the University of Bonn and offers a stimulating research environment through its international network, workshops and conferences, data service, project support, research visits and doctoral program. IZA engages in (i) original and internationally competitive research in all fields of labor economics, (ii) development of policy concepts, and (iii) dissemination of research results and concepts to the interested public.
\end{abstract}

IZA Discussion Papers often represent preliminary work and are circulated to encourage discussion. Citation of such a paper should account for its provisional character. A revised version may be available directly from the author. 


\begin{abstract}

\section{Temporary Jobs and the Severity of Workplace Accidents*}

From the point of view of workplace safety, it is important to know whether having a temporary job has an effect on the severity of workplace accidents. We present an empirical analysis on the severity of workplace accidents by type of contract. We used micro data collected by the Italian national institute managing the mandatory insurance against work related accidents. We estimated linear models for a measure of the severity of the workplace accident. We controlled for time-invariant fixed effects at worker and firm levels to disentangle the impact of the type of contract from the spurious one induced by unobservables at worker and firm levels. We found that workers with a temporary contract, if subject to a workplace accident, were more likely to be confronted with severe injuries than permanent workers. When correcting the statistical analysis for injury under-reporting of temporary workers, we found that most of, but not all, the effect is driven by the underreporting bias. The effect of temporary contracts on the injury severity survived the inclusion of worker and firm fixed effects and the correction for temporary workers' injury underreporting. This however does not exclude the possibility that, within firms, the nature of the work may vary between different categories of workers. For example, temporary workers might be more likely to be assigned by the employer dangerous tasks because they might have less bargaining power. The findings will be of help in designing public policy effective in increasing temporary workers' safety at work and limiting their injury under-reporting.
\end{abstract}

JEL Classification: $\quad \mathrm{C} 23, \mathrm{~J} 41, \mathrm{~J} 81$

Keywords: workplace accidents, injury severity, temporary jobs, contract type, injury under-reporting

Corresponding author:

Matteo Picchio

Department of Economics and Social Sciences

Marche Polytechnic University

Piazzale Martelli 8

60121 Ancona

Italy

E-mail: m.picchio@univpm.it

\footnotetext{
* The authors thank Paola Monti and Chiara Serra for their help in collecting the data and Andrea Albanese, Rafael Lalive, Paolo Pinotti, Knut Røed and the participants in the Ravenna fRdBconference on Health and Work Safety for comments on a very preliminary version of this study.
} 


\section{Introduction}

Accidents at work vary considerably depending upon the economic activity (Eurostat, 2014). Within the European Union (28 countries) in 2012, the construction, manufacturing, transportation and storage and agriculture, forestry and fishing sectors together accounted for just over two thirds of all fatal accidents at work and over half of all serious accidents. EU-28 data for 2012 shows that there were two types of common injury, namely, wounds and superficial injuries (about $30 \%$ of the total) and dislocations, sprains and strains (about 25\%). Around one in ten accidents resulted in concussion and internal injuries, while a similar proportion of accidents concerned bone fractures.

In their overview of the literature on occupational safety and health Pouliakas and Theodossiou (2013) mention that, in addition to gender and economic sector, other important determinants of workplace accidents are firm size, age and educational attainment of the worker, characteristics of the job such as long hours of work, monotony, lack of autonomy at work and job dissatisfaction. Furthermore, workers on temporary and casual contracts seem to be more susceptible to workplace accidents. A job is temporary if employer and employee agree that the job relationship ends when some objective conditions, like a specific date, the completion of a task or the return of a sick employee, are met. Typical cases of temporary jobs are fixed-term jobs, in which the end date of the job relationship is explicitly stated in the job contract, persons with seasonal employment and temporary-work-agency workers. The higher probability of temporary workers to suffer a workplace accident might be due to the fact that they have less experience with the workplace and because firms have less incentive to provide them with workplace safety training (Pouliakas and Theodossiou, 2013).

It is important to investigate the relationship between the type of job contract and workplace accidents since the nature of the labor market is changing. Over the past decade, the share of workers with flexible labor contracts increased and is expected to continue to rise. As shown in graph a) of Figure 1, in Italy the share of temporary jobs among total salaried employment is growing, particularly among young workers. Whereas the share of temporary workers among old workers (50-64) stayed roughly constant over the time period 1983-2015, the share of temporary workers went up from $8 \%$ to $16 \%$ for prime age female workers and from $4 \%$ to $14 \%$ for prime age male workers. The change in the share of temporary workers is spectacular 
among young workers, as it increased from $12 \%$ to $59 \%$ for young women and from $11 \%$ to $56 \%$ for young men. Graph b) of Figure 1 reports the share of temporary employees by sector of activity. It shows that it increased in all sectors of activity and nowadays one third $(33.1 \%)$ of salaried workers are employed on a temporary basis in agriculture and about $10 \%$ in the manufacturing and services.

Figure 1: Share of temporary workers in employment in Italy by: a) age and gender; b) sector of activity

a) Share of temporary workers by age and gender

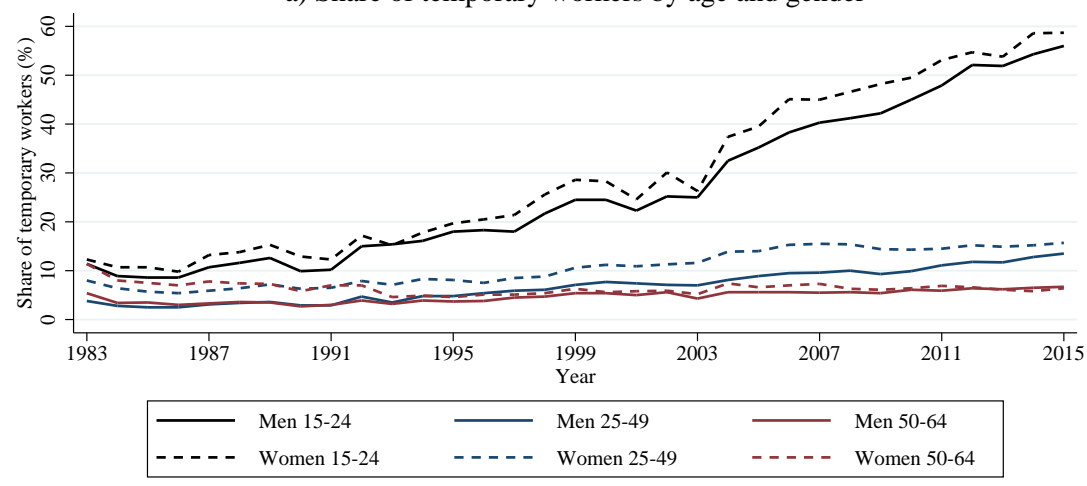

b) Share of temporary workers by sector of activity

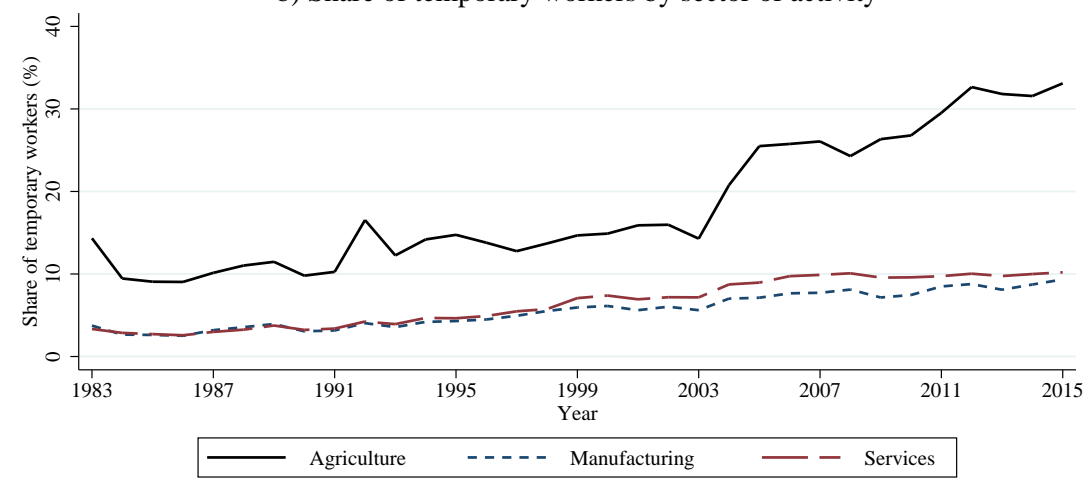

Source: Eurostat, Labor Force Survey, available on-line at http://ec.europa.eu/eurostat/web/lfs/data/database.

Notes: An employee is a temporary worker if it is stated in the job contract that the job relationship ends when some objective conditions, like a specific date, the completion of a task or the return of a sick employee, are fulfilled. Workers with seasonal employment, temporarywork-agency workers, fixed-term workers are typical cases of temporary employees.

From the point of view of workplace safety it is important to know whether temporary workers are more likely to suffer from severe workplace accidents. Previous studies on contract type and workplace accidents are focused on the incidence of workplace accidents and inconclusive on the effect of temporary contracts. Amuedo-Dorantes (2002) found that in Spain temporary employees experience worse working conditions than permanent workers. However, 
once working conditions are accounted for, temporary workers are not more likely to have a workplace accident. Guadalupe (2003), also using Spanish data, found that the accident rate of fixed-term workers is 5 percentage points higher than the one of permanent contract workers. García-Serrano et al. (2010) analyzing Spanish workplace accidents found that temporary help agency workers are less likely to be confronted with an accident. Bena et al. (2013) analyzing Italian data found that job tenure is inversely associated with injury risks.

An important issue in assessing workplace safety is the reporting behavior of workers. Boone and van Ours (2006), Davies et al. (2009) and Boone et al. (2011) suggested that cyclical fluctuations in observed workplace accidents are related to reporting behavior rather than caused by changes in workplace safety. Under-reporting occurs because workers are afraid that reporting an accident may lead to job loss or denial of promotion. The under-reporting is more likely to occur in times of high unemployment and may be more likely by workers on temporary jobs. Probst et al. (2013) found indeed that accident under-reporting is more relevant when workers' perception of job insecurity is larger.

Using administrative data on workplace accidents for Italy covering the period 2009-2013, we investigated the determinants of the severity of workplace accidents, focusing on the question whether the nature of the contract matters. More in detail, we aimed at answering the following three main research questions. First, for similar employees working in similar firms, were temporary workers subject to more severe workplace accidents than permanent workers? If so, this might signal that firms were using temporary employees to perform dangerous tasks, given that temporary workers might have less bargaining power. Second, what was the role played by the working time schedule on the severity of temporary workers' accident? The impact of the temporary nature of a job contract on injury severity could be heterogeneous. It might indeed be more pronounced for temporary employees working full-time. If temporary workers were at higher risk of severe injuries, having a job schedule with longer working hours could reinforce the risk of incurring in severe injuries. See e.g. Dembe et al. (2006) for an analysis of the impact of long hours of work on occupational injuries. However, other explanations could be at stake for an eventual higher risk of severe injuries for temporary workers. For example, it could be a statistical artefact stemming from temporary workers under-reporting minor injuries. Temporary workers might be indeed less inclined than permanent workers to report an injury, because of the fear of being stigmatized as "bad workers" and fired (Guadalupe, 2003). 
Since this under-reporting behavior is expected to be more important for minor accidents, the average severity of temporary workers' accidents could have displayed an upward bias. This led to our third research question: how important is the difference in reporting behavior between temporary and permanent worker when analyzing the impact of different contractual arrangements on the severity of workplace accidents? Evidence of temporary workers under-reporting work related accidents has important implications for public policy. We found this evidence and formulated recommendations in order to reduce it.

\section{Methods}

\subsection{Data source}

In order to answer our research questions, we exploited micro data on workplace accidents gathered by the Italian National Institute for Insurance against Occupational Accidents (INAIL). INAIL is the Italian national agency monitoring work related illness and injury and managing the mandatory insurance against work related accidents. Work related accidents include workplace accidents, students' accidents at school and accidents while the worker is commuting for home to the workplace or vice versa. Commuting accidents are compensated as if they occurred at the workplace.

Firms are obliged to electronically communicate to INAIL every work related accident resulting in an injury whose recovery time, certified by a physician, exceeds the three days after the day in which the accident occurred. Firms are not required to report to INAIL on minor accidents, i.e. those with an injury recovery time shorter than three days. In case of mandatory communication, employers must report on the accident within two days from the moment in which they receive the medical certificate and within one day in case of worker's death. Employers that do not comply with the mandatory communication of the accident to INAIL are fined between $€ 1,290$ and $€ 7,745$ per injured worker (Art. 1 and 2 of Law 561/1993 and Art. 1, paragraph 1177 of Law 296/2006).

The INAIL dataset we used for our research contains information on all the work related accidents which took place in Italy between January 1, 2009 and December 31, 2013. The dataset contains 4,006,769 records of work related accidents. Only some special categories of 
workers, like firemen, policemen, servicemen and journalists, are not covered by INAIL but by other insurers and are therefore not represented in the INAIL dataset. The unit of observation is the accident. For each accident, the dataset contains a set of characteristics at different levels.

First, we have characteristics pertaining the accident: the date of the accident and, in case of death, the date of death, the Italian province where the accident occurred, whether a vehicle was involved and whether the accident was at the workplace or in commuting.

Second, we have three measures of the severity of the injury: i) number of days of injury recovery certified by a physician; ii) permanent physical damage with severity measured on a scale from 0 to 100 ; iii) whether the accident caused the death of the worker.

Third, at firm level, we know the sector of activity (2-digit NACE 2007) and firm and plant identifiers. These identifiers allow to understand the number of accidents which took place within the same firm and in the same plant, respectively.

Finally, the dataset contains individual characteristics of the injured person: gender, country of birth, date of birth, an individual identifier allowing to detect whether the same person had multiple accident during the observed time window and detailed information on the employment position (whether salaried workers, self-employed, student or homemaker). Furthermore, salaried workers can be distinguished on the basis of:

- The contractual duration of the job relationship. The distinction between temporary and permanent workers depends on the presence of the termination date of the job relationship in the contract. If the termination date is present, the worker is classified as temporary. The category of temporary workers include therefore also workers for a temporary work agency (TWA), if the job contract with the TWA has a termination date, and seasonal workers.

- The number of contractual working hours. A job is declared to be part-time or fulltime by the employer when filling in the INAIL questionnaire to report on the workplace accident. A job is part-time when the number of working hours are smaller than the normal working hours as stated by the national contractual agreement.

- The kind of relation with the employer, i.e. standard employee, apprentice, TWA worker or continuous collaborator. Continuous collaborators are, as regulated by the Law 30/2003, hybrids between employees and self-employed workers. Officially, continuous collabo- 
rators are self-employed subcontractors and, as such, they are largely excluded from most of the employment protection and social security. However, the working conditions of continuous collaborators are similar, de facto, to those of standard employees.

In the empirical analysis below, we focused on employees, including continuous collaborators, apprentices and TWA workers, and disregarded information on accidents of self-employed workers, students and homemakers.

\subsection{Estimating the impact of contract type on workplace accidents injury severity}

The starting point of our empirical investigation was the analysis of the impact on the severity of workplace accidents of the type of contract, distinguishing workers in permanent and full-time, permanent and part-time, temporary and full-time and temporary and part-time. The outcome variable of primary interest, as a measure of the severity of the work related accident, was the number of days of injury recovery as certified by a physician. As such it never takes negative values. If, in modeling its conditional mean, we used a linear specification in the observed regressors, we could have had negative predictions for the number of days of recovery. In order to avoid such a problem, we took the natural logarithm of the number of days of recovery and then specify its conditional mean using a standard linear specification. Formally, denote by $y_{i t}$ the natural logarithm of the number of days of injury recovery from accident $t$ for worker $i$, with $t=1, \ldots, T$ and $i=1, \cdots, N$. In error form, the equation describing the outcome variable for individual $i$ experiencing accident $t$ was assumed to be

$$
y_{i t}=\mathbf{t c}_{i t}^{\prime} \boldsymbol{\alpha}+\mathbf{x}_{i t}^{\prime} \boldsymbol{\beta}+u_{i t}
$$

where:

- $\mathbf{t c}_{i t}$ is a set of dummy variables indicating whether the worker fell into one of the following four mutually exclusive contract type: permanent and full-time, permanent and part-time, temporary and full-time or temporary and part-time. $\mathbf{t} \mathbf{c}_{i t}$ is a vector of zeros if the worker had the standard working arrangement: full-time and permanent. 
- $\boldsymbol{\alpha}$ is the conformable vector of coefficients, i.e. the effect of having a particular type of contract on workplace injury severity.

- $\mathbf{x}_{i t}$ is a $K \times 1$ vector of control variables containing a constant, worker's characteristics (age, gender, nationality, type of worker), characteristics of the establishment (sector and geographical area), characteristics of the accident (whether a vehicle was involved and year and month of the accident) and eventually worker or/and firm fixed effects. $\boldsymbol{\beta}$ is its conformable vector of coefficients.

- $u_{i t}$ is an idiosyncratic error term with conditional mean equal to zero.

Estimation of Equation (1) by Ordinary Least Squares (OLS) returns unbiased estimates of the effect of the contract type on the severity of the injury under the assumption that the regressors are uncorrelated to the error term. This assumption holds if there are no other predictors of the dependent variable $y_{i t}$ which are, at the same time, correlated to the regressors of interest in the right-hand side of Equation (1). If these uncontrolled predictors are omitted from the model specification, an omitted variable problem arises and the OLS estimator is biased and inconsistent. Given our limited set of control variables, there are good reasons to believe that there might be unobserved firm and worker characteristics determining both the contract type $\mathbf{t c}_{i t}$ and the type of accident and, thereby, the severity of the injury. If so, it would be difficult to interpret the estimated parameters and disentangle the impact of contract type from the spurious one determined by unobserved characteristics at firm and worker level. For example, firms using special production technologies or with final products more affected by international competition might be more likely to demand temporary workers and have more risky working environments. If this is the case and we cannot control for the exposure to international competition, the estimated impact of the contract type will incorporate the one of the omitted variable: we would be unable to disentangle the true effect of the contract type from the spurious one of the degree of market competition. More productive and able workers might be more likely to get a permanent job and, since they might be organized and precise in their tasks, less likely to get involved in serious accidents. Once again, if this is the case and we cannot control for workers' ability, we cannot disentangle the impact of contract type from the one coming from unobserved ability. 
In order to overcome these omitted variable problems, we estimated different versions of Equation (1), after augmenting it by fixed effects at firm or/and worker level. The inclusion among the set of explanatory variables of firm fixed effects removed the omitted variable bias stemming from unobserved firm characteristics determining both the type of accident, and therefore the severity of the injury, and the type of contract. Augmenting Equation (1) by worker fixed effects eliminated, from the estimated impact of the contract type on injury severity, the spurious effect induced by unobserved heterogeneity at worker level correlated both to the contract type and the injury severity.

The identification of the effect of the type of contract on injury severity was based on different assumptions and on variation of different sources, depending on whether we controlled or not for fixed effects at worker and firm level. If we included in Equation (1) neither the firm nor the worker fixed effects and estimated it by OLS, we identified the effect of contract type under the assumption that there were no unobserved worker and firm characteristics affecting both the contract type and the injury severity. When we included the firm fixed effects in Equation (1), we removed the spurious effect due to firm heterogeneity and identification was based on the within firm presence of accidents of workers with different types of contracts. Finally, when we controlled for the fixed effect at worker level, we identified the effect of contract type exploiting information on the injury severity from those workers who had multiple accidents in the time window 2009-2013 under different contract types. This identification strategy has some pros but also some cons. On the one hand, controlling for workers' fixed effects removed from the estimated effect the spurious component due to the presence of heterogeneity at individual level which was constant across multiple accidents, like for instance ability, productivity and skills. On the other hand, since most of the workers in our dataset experienced only one accident in the observation period, the identification of the effect hinged on a small fraction of the original sample and on the implicit assumption that the change in the contract type was not caused by the severity of a previous injury (strict exogeneity assumption).

\subsection{Estimation strategy when correcting for under-reporting}

The evaluation of the causal effect of the type of contract on injury severity might be problematic due to the under-reporting of occupational injuries. Under-reporting is indeed very 
well-known to affect occupational injury data (see e.g. Galizzi et al., 2010; Rosenman et al., 2006; Shannon and Lowe, 2002; Tucker et al., 2014), and it might be significantly related to the type of contract. Firing a temporary worker is much easier than firing a permanent worker in Italy. Dismissing a temporary worker is indeed just a matter of waiting for the end of the contract, whilst firing costs of a permanent worker might imply more than 20 months of gross wage if declared unfair in court. Hence, temporary workers might be much less inclined than permanent workers to report an occupational injury because of the fear of being stigmatized as "bad workers" and, as a consequence, fired (Guadalupe, 2003). Since it is plausible that it is more difficult, for both the firms and the injured workers, to avoid reporting severe injuries, the contract type differential in under-reporting is expected to be more important at the bottom of the distribution of the injury severity variable. In other words, minor accidents of temporary workers could be underrepresented in our dataset, with the consequence that the observed mean of the number of days of injury recovery could be upward biased.

We exploited the information on commuting accidents to get rid of the under-reporting bias in a difference-in-differences (DD) estimation framework. In Italy, accidents while commuting from home to the workplace and vice versa are considered as work related accidents: INAIL compensates the injured worker as if the accident took place at the workplace. If we compare the injury severity of a temporary and a permanent worker incurred in a commuting accident with the same observables, like gender, nationality, age, sector of activity, geographical location, moment of time (month and year) and eventually working for the same firm, on average we should not detect any difference in the severity of their injuries. If we do, it might be that the difference is due to temporary workers under-reporting minor injuries for the fear of the above-mentioned stigma. It is unlikely that eventual discrepancies in the average severity of a commuting accident between temporary and permanent workers are due instead to different exposure to workplace hazards. If so, commuting accidents can be exploited to identify the under-reporting bias by comparing the average injury severity of commuting accidents for workers with different contract type and, under the assumption that the same under-reporting bias is present also in workplace accidents, disentangle the spurious effect of the contract type due to under-reporting bias from the true effect of the contract type.

From the operational point of view, we proceeded as follows. First, we included in the sample also commuting accidents. Second, similarly to the model specification in Equation 
(1), we wrote down a linear model in error form for the natural logarithm of the days of injury recovery for individual $i$ experiencing work related accident $t$, with $i=1, \ldots, N$ and $t=$ $1, \ldots, T$, as

$$
y_{i t}=\mathbf{t c}_{i t}^{\prime} \boldsymbol{\alpha}+\left(w a_{i t} \cdot \mathbf{t} \mathbf{c}_{i t}\right)^{\prime} \boldsymbol{\delta}_{D D}+\mathbf{x}_{i t}^{\prime} \boldsymbol{\beta}+\left(w a_{i t} \cdot \mathbf{x}_{i t}\right)^{\prime} \boldsymbol{\gamma}+u_{i t},
$$

where $w a_{i t}$ is a dummy indicator equal to one if the accident took place at work and zero if it was in commuting. The difference between Equations (1) and (2) consists in: i) the presence of the dummy indicator $w a_{i t}$; ii) the inclusion of a full set of interactions between this dummy variable $w a_{i t}$ and all the other regressors $\left[\mathbf{t c}_{i t}, \mathbf{x}_{i t}\right]^{\prime}$. Lastly, we estimated Equation (2) by OLS. The OLS estimate of $\boldsymbol{\delta}_{D D}$ is the treatment effect, i.e. the causal effect of having a particular type of contract on workplace injury severity, once we net out possible under-reporting biases of temporary workers. The OLS estimate of the parameter vector $\gamma$ captures the difference in the injury severity between accidents at work and in commuting, which is allowed in our model specification to vary across different values of the covariates $\mathbf{x}_{i t}$.

In order to clarify the claim that $\boldsymbol{\delta}_{D D}$ identifies the causal effect of the contract type on workplace injury severity, under the zero mean assumption of the error term $u_{i t}$, from Equation (2) we can write the following conditional expected values:

$$
\begin{aligned}
\mathrm{E}\left[y_{i t} \mid \mathbf{x}_{i t}, w a_{i t}=1, \mathbf{t} \mathbf{c}_{i t}=\mathbf{0}\right] & =\mathbf{x}_{i t}^{\prime} \boldsymbol{\beta}+\mathbf{x}_{i t}^{\prime} \boldsymbol{\gamma}, \\
\mathrm{E}\left[y_{i t} \mid \mathbf{x}_{i t}, w a_{i t}=0, \mathbf{t} \mathbf{c}_{i t}=\mathbf{0}\right] & =\mathbf{x}_{i t}^{\prime} \boldsymbol{\beta}, \\
\mathrm{E}\left[y_{i t} \mid \mathbf{x}_{i t}, w a_{i t}=1, \mathbf{t} \mathbf{c}_{i t} \neq \mathbf{0}\right] & =\mathbf{x}_{i t}^{\prime} \boldsymbol{\beta}+\mathbf{x}_{i t}^{\prime} \boldsymbol{\gamma}+\mathbf{t c}_{i t}^{\prime} \boldsymbol{\alpha}+\mathbf{t} \mathbf{c}_{i t}^{\prime} \boldsymbol{\delta}_{D D}, \\
\mathrm{E}\left[y_{i t} \mid \mathbf{x}_{i t}, w a_{i t}=0, \mathbf{t c} \mathbf{c}_{i t} \neq \mathbf{0}\right] & =\mathbf{x}_{i t}^{\prime} \boldsymbol{\beta}+\quad \mathbf{t c}_{i t}^{\prime} \boldsymbol{\alpha} .
\end{aligned}
$$

Equations (3) and (4) are the conditional expectations of the injury severity for workers with a permanent and full-time arrangement, in case of accident at work and in commuting, respectively. Equations (5) and (6) are the counterparts for workers with a non-standard contract type. Differencing the conditional expectation of non standard workers eliminates the fixed effects $\mathbf{x}_{i t}^{\prime} \boldsymbol{\beta}$ and the drift $\mathbf{t c}_{i t}^{\prime} \boldsymbol{\alpha}$ associated to the type of contract that might be due, for instance, to 
under-reporting, i.e.

$$
\mathrm{E}\left[y_{i t} \mid \mathbf{x}_{i t}, w a_{i t}=1, \mathbf{t} \mathbf{c}_{i t} \neq \mathbf{0}\right]-\mathrm{E}\left[y_{i t} \mid \mathbf{x}_{i t}, w a_{i t}=0, \mathbf{t} \mathbf{c}_{i t} \neq \mathbf{0}\right]=\mathbf{x}_{i t}^{\prime} \boldsymbol{\gamma}+\mathbf{t c}_{i t}^{\prime} \boldsymbol{\delta}_{D D}
$$

This clarifies how we exploited the information in commuting accidents to get rid of underreporting biases. The same difference for standard workers yields

$$
\mathrm{E}\left[y_{i t} \mid \mathbf{x}_{i t}, w a_{i t}=1, \mathbf{t} \mathbf{c}_{i t}=\mathbf{0}\right]-\mathrm{E}\left[y_{i t} \mid \mathbf{x}_{i t}, w a_{i t}=0, \mathbf{t} \mathbf{c}_{i t}=\mathbf{0}\right]=\mathbf{x}_{i t}^{\prime} \boldsymbol{\gamma}
$$

which isolates the effect of a workplace accident, compared to a commuting accident, on injury severity. Then, by taking the difference of the differences in Equations (7) and (8), we get rid of $\mathbf{x}_{i t}^{\prime} \gamma$ and are left with $\mathbf{t c}_{i t}^{\prime} \boldsymbol{\delta}_{D D}$, which is what we aim at identifying.

Conditional on observables, the identification of the effect of contract type on workplace injury severity through a DD approach is based on some underlying assumptions, implicit in the model specification. First, ceteris paribus, workers with a non standard job arrangement experience drifts $\left(\mathrm{x}_{i t}^{\prime} \gamma\right)$ in the injury severity similar to those of permanent and full-time employees. This assumption is the same as the parallel trend assumption per each cell identified by set of observables in a standard DD framework (Abadie, 2005). Second, ceteris paribus, workers with a workplace accident experience drifts $(\boldsymbol{\alpha})$ in the injury severity similar to those of workers with a commuting accident. In other words, we required that, given the same type of contract, workers have the same reporting behavior of their accidents at work and in commuting.

As we did in the benchmark analysis based only on accidents at work, we could augment Equation (2) by fixed effects at firm and/or worker level. However, if we introduced worker fixed effects, the identification of the effect of the type of contract on the severity of the workplace accidents would be based on those workers with multiple accidents of both types, in commuting and at work. When a worker experiences an accident, either in commuting or at work, for a while she will be less likely to undergo the accident of the other type, since the injured worker will be absent from work for some days. In other words, at worker level, one type of accident generates a potentially relevant crowding out effect from the other type of accident. This means that, with worker fixed effects, the effect is identified on a small sub-sample that is 
endogenously selected, because the less severe is the accident (the smaller the number of days of injury recovery), the larger the probability of observing the same worker in both types of accidents. This is the reason why, when we conducted the DD analysis, we did not estimate the equation with worker fixed effects.

\section{Results}

\subsection{Sample characteristics}

The original INAIL dataset contained 4,006,769 records of accidents. We selected all the records that INAIL officially recognized as work related accidents and deleted all the records that received a negative evaluation by INAIL or that were still under inquiry. This selection reduced the dataset to $3,257,083$ observations. According to the institutional set-up, it was not mandatory for the employer to communicate minor accidents. Nonetheless, some employers did communicate them. Since these minor accidents were very likely to be largely underrepresented, we deleted accidents causing three or less days of injury recovery (excluding the day of the accident), leaving us with 2,739,805 accidents. After dropping students, homemakers and self-employed workers and restricting the sample to workers between 15 and 64 years of age, the sample size shrank to $1,809,244$ records. Then, we deleted records with missing observations for the sector of activity or the region of the firm, which further reduced the sample to $1,650,350$ reported accidents.

The focus of our analysis was on the relationship between the type of contract and the severity of the injury, conditional on having a workplace accident. As an indicator of the severity of the accident, we used the number of days of injury recovery that INAIL assigned to the injured worker. In case of immediate death, this information is not available. We therefore restricted the sample to those workers who survived the accident (deleting 2,554 records). In order to avoid possible coding mistakes in the variable measuring the number of days of injury recovery, we further restricted the sample by removing observations in the last percentile of the distribution of the days of injury recovery. The 99th percentile of the distribution of the number of days of injury recovery was 247 days. We were left with 1,630,478 records of which 1,350,593 were workplace accidents and the remaining 279,885 were commuting accidents. The workplace 
accidents belonged to 1,152,627 different workers, employed in 304,258 different firms. The commuting accidents (17.2\% of the reported accidents), which we initially removed from our sample, were exploited later to assess the importance of eventual under-reporting biases.

Table 1 reports summary statistics of the days of injury recovery from a workplace accident, for the whole sample and by the type of contract and working time. For the whole sample, the average number of days of injury recovery was about 29. Part-time workers were on average less likely to experience severe accidents, independently on whether they were temporary or permanent workers. The average number of days of injury recovery for part-timers was indeed equal to 26 days if working with a temporary arrangement and to 27 if working with a permanent contract. The same figures were respectively equal to 34 and 30 for full-timers. Temporary and full-time workers were therefore those suffering, on average, more severe accidents. By looking at the percentiles of the distribution of the days of injury recovery, we noted that the differences in the means are larger than the differences in the medians. The percentiles were indeed quite homogeneous across the different types of workers up to the median. They started to be quite different after the 75 th percentile. It was hence the right tail of the distributions which explained most of the observed difference in the means. Figure 2 displays the cumulative distribution functions of the natural logarithm of the days of injury recovery. It offers an alternative way of looking at differences in the distribution of the days of injury recovery across different types of workers. It confirms that the difference in the mean of the days of injury recovery between temporary and permanent full-timers was mostly induced by the fact that temporary full-timers were more likely to experience quite severe workplace accidents.

Table 1: Summary statistics of the days of injury recovery by type of contract and working time.

\begin{tabular}{lccccc}
\hline \hline & \multicolumn{3}{c}{ Full-time job } & \multicolumn{2}{c}{ Part-time job } \\
& Whole sample & Temporary & Permanent & Temporary & Permanent \\
\hline Mean & 29.4 & 34.2 & 29.7 & 26.3 & 27.4 \\
Standard deviation & 34.8 & 42.9 & 35.0 & 31.9 & 32.1 \\
Selected percentiles & & & & & \\
$\quad$ 5th & 5 & 5 & 5 & 5 & 5 \\
10th & 6 & 6 & 6 & 6 & 6 \\
25th & 9 & 8 & 9 & 8 & 8 \\
50th & 16 & 17 & 16 & 15 & 15 \\
75th & 35 & 40 & 35 & 30 & 32 \\
90th & 69 & 88 & 70 & 62 & 63 \\
95th & 101 & 132 & 102 & 91 & 93 \\
\hline \# of accidents & $1,350,593$ & 44,420 & $1,056,117$ & 33,739 & 216,317 \\
\hline
\end{tabular}

Table 2 displays summary statistics of the explanatory variables used in the regression anal- 
Figure 2: The cumulative density distributions of the natural logarithm of the days of injury recovery by type of contract and working time
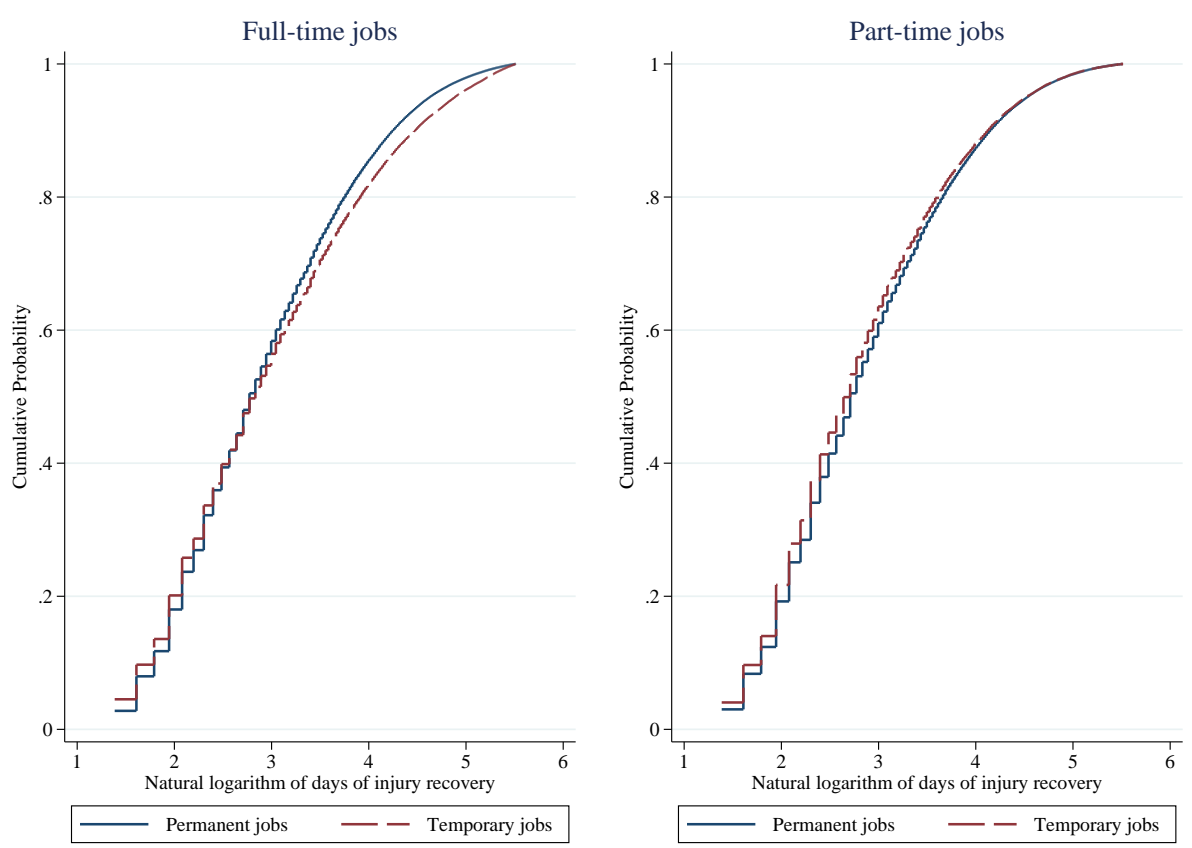

ysis. The explanatory variables of primary interest were the type of contract, distinguished on the basis of the contractual duration of the job relationship (whether temporary or open-ended contract) and of the number of contractual working hours (part-time or full-time). Most of workers experiencing a workplace accident were permanent and full-time workers (78.2\%), whereas temporary workers amounted to about $5.8 \%$ of the sample. Less than $1.5 \%$ of the workers were non-standard employees and were instead either apprentices, TWA workers, or continuous collaborators. We also had information on the age of the worker (on average 40.8 years old), gender (27.5\% are female), nationality ( $84.7 \%$ are Italian), whether a vehicle was involved in the accident ( $6.4 \%$ of the records), the sector of economic activity, the region of the firm and the date of the accident. Over the years, the number of accidents decreased, perhaps as a consequence of the economic crisis and the resulting reduction in the number of employees.

Table 3 shows the distribution of firms by the number of accidents and the distribution of workers by the number of multiple accidents they experienced. It therefore gives an overview of the type of multiple observation per firm or per worker that we exploited in the regression analysis to identify the firm or the worker fixed effects. As mentioned at the end of Subsection 
Table 2: Summary statistics

\begin{tabular}{|c|c|c|c|c|}
\hline Variable & Mean & Std. Dev. & Min. & Max. \\
\hline Age & 40.8 & 10.4 & 15 & 64 \\
\hline Female & 0.275 & 0.447 & 0 & 1 \\
\hline Italian & 0.847 & 0.360 & 0 & 1 \\
\hline Vehicle involved & 0.064 & 0.245 & 0 & 1 \\
\hline \multicolumn{5}{|l|}{ Contract type } \\
\hline Permanent and full-time job & 0.782 & 0.413 & 0 & 1 \\
\hline Permanent and part-time job & 0.160 & 0.367 & 0 & 1 \\
\hline Temporary and full-time job & 0.033 & 0.178 & 0 & 1 \\
\hline Temporary and part-time job & 0.025 & 0.156 & 0 & 1 \\
\hline \multicolumn{5}{|l|}{ Worker type } \\
\hline Standard employee & 0.986 & 0.118 & 0 & 1 \\
\hline Apprentice & 0.004 & 0.065 & 0 & 1 \\
\hline TWA worker & 0.004 & 0.061 & 0 & 1 \\
\hline Continuous collaborator & 0.006 & 0.078 & 0 & 1 \\
\hline \multicolumn{5}{|l|}{ Sector } \\
\hline Manufacturing & 0.285 & 0.451 & 0 & 1 \\
\hline Construction & 0.117 & 0.322 & 0 & 1 \\
\hline Other & 0.598 & 0.490 & 0 & 1 \\
\hline \multicolumn{5}{|c|}{ Geographic location of the establishment } \\
\hline North-West & 0.301 & 0.458 & 0 & 1 \\
\hline North-East & 0.289 & 0.453 & 0 & 1 \\
\hline Centre & 0.204 & 0.403 & 0 & 1 \\
\hline South & 0.206 & 0.405 & 0 & 1 \\
\hline \multicolumn{5}{|l|}{ Year } \\
\hline 2009 & 0.226 & 0.418 & 0 & 1 \\
\hline 2010 & 0.222 & 0.416 & 0 & 1 \\
\hline 2011 & 0.204 & 0.403 & 0 & 1 \\
\hline 2012 & 0.176 & 0.381 & 0 & 1 \\
\hline 2013 & 0.171 & 0.377 & 0 & 1 \\
\hline \multicolumn{5}{|l|}{ Month } \\
\hline January & 0.075 & 0.264 & 0 & 1 \\
\hline February & 0.080 & 0.271 & 0 & 1 \\
\hline March & 0.088 & 0.283 & 0 & 1 \\
\hline April & 0.080 & 0.271 & 0 & 1 \\
\hline May & 0.092 & 0.288 & 0 & 1 \\
\hline June & 0.092 & 0.288 & 0 & 1 \\
\hline July & 0.099 & 0.299 & 0 & 1 \\
\hline August & 0.068 & 0.251 & 0 & 1 \\
\hline September & 0.089 & 0.284 & 0 & 1 \\
\hline October & 0.089 & 0.284 & 0 & 1 \\
\hline November & 0.082 & 0.274 & 0 & 1 \\
\hline December & 0.069 & 0.253 & 0 & 1 \\
\hline \# of accidents & \multicolumn{4}{|c|}{$1,350,593$} \\
\hline
\end{tabular}


2.2, multiple observations of workplace accidents per worker or per firm were indeed needed to identify the effect of the contract type when we included fixed effects at worker or firm level, respectively.

Table 3: Distribution of firms and workers by the number of accidents

\begin{tabular}{|c|c|c|c|c|}
\hline \multirow[b]{2}{*}{ Number of accidents } & \multicolumn{2}{|c|}{ Firms } & \multicolumn{2}{|c|}{ Workers } \\
\hline & $\begin{array}{r}\text { Absolute } \\
\text { frequency }\end{array}$ & $\begin{array}{r}\text { Relative } \\
\text { frequency }\end{array}$ & $\begin{array}{r}\text { Absolute } \\
\text { frequency }\end{array}$ & $\begin{array}{r}\text { Relative } \\
\text { frequency }\end{array}$ \\
\hline 1 & 172,621 & 56.74 & 997,893 & 86.58 \\
\hline 2 & 53,182 & 17.48 & 123,876 & 10.75 \\
\hline 3 & 23,924 & 7.86 & 22,709 & 1.97 \\
\hline 4 & 13,363 & 4.39 & 5,620 & 0.49 \\
\hline 5 & 8,548 & 2.81 & 1,567 & 0.14 \\
\hline 6 & 5,780 & 1.90 & 563 & 0.05 \\
\hline 7 & 4,049 & 1.33 & 220 & 0.02 \\
\hline 8 & 3,017 & 0.99 & 97 & 0.01 \\
\hline 9 & 2,338 & 0.77 & 46 & 0.00 \\
\hline More than 9 & 17,436 & 5.73 & 36 & 0.00 \\
\hline Number of units & \multicolumn{2}{|c|}{304,258} & \multicolumn{2}{|c|}{$1,152,627$} \\
\hline Maximum number of accidents within unit & \multicolumn{2}{|c|}{8,189} & \multicolumn{2}{|c|}{15} \\
\hline
\end{tabular}

In order to correct the estimations for accident under-reporting of temporary workers, we exploited commuting accidents as described in Subsection 2.3. From 2009 until 2013 there were about 280,000 commuting accidents in Italy, $17 \%$ of the total work related accidents. Table 4 reports descriptive statistics of the outcome variable when we included also commuting accidents in the estimation sample. Accidents in commuting were more severe on average and also across all the selected percentiles. The average number of days of injury recovery for commuting accidents was 36.3 days, against 29.4 days of workplace accidents. Figure 3 illustrates the cumulative distribution functions of the days of injury recovery, distinguishing between accidents in the workplace and in commuting. It shows that the probability of experiencing an accident more severe than a given number of days of injury recovery was always higher for commuting accidents, for every value of the days of injury recovery.

Table 4: Summary statistics of days of injury recovery for accidents at the workplace and in commuting

\begin{tabular}{|c|c|c|c|c|c|c|c|c|}
\hline Days of absence & Observations & Mean & Std. Dev. & Min. & 25 th perc. & Median & 75th perc. & Max. \\
\hline Either at the workplace or in commuting & $1,630,478$ & 30.6 & 35.6 & 4 & 9 & 17 & 37 & 247 \\
\hline \multicolumn{9}{|l|}{ By accident type } \\
\hline At the workplace & $1,350,593$ & 29.4 & 34.8 & 4 & 9 & 16 & 35 & 247 \\
\hline In commuting & 279,885 & 36.3 & 38.9 & 4 & 11 & 22 & 46 & 247 \\
\hline
\end{tabular}


Figure 3: The cumulative distribution functions of the natural logarithm of the days of injury recovery for accidents at the workplace and in commuting

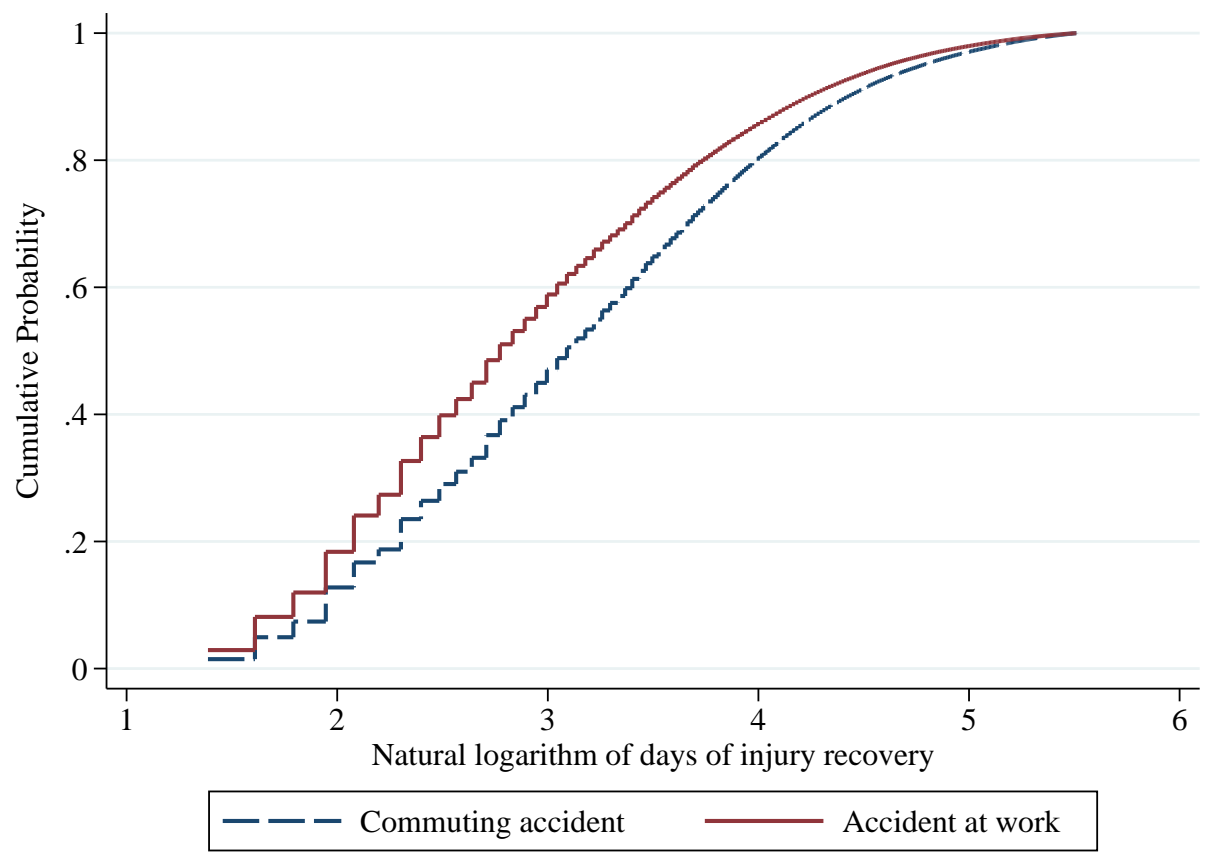

\subsection{Parameter estimates of the benchmark model}

Table 5 reports the OLS estimation results of Equation (1) without controlling for fixed effects at worker or firm level. Workers with a full-time temporary job suffered from more severe injuries than full-time permanent workers. The days of injury recovery were almost $15 \%$ larger for temporary full-timers than for permanent full-timers. Part-timers were significantly less likely to experience severe injuries than full-timers. The days of injury recovery in case of accident for temporary (permanent) part-timers were 1.6\% (0.5\%) smaller than those of fulltime permanent workers.

Furthermore, we found that standard employees were more likely to suffer more severe injuries than apprentices, TWA workers and continuous collaborators. Women and non-Italians were subject to less severe injuries than their counterparts. Injury severity rose with age, maybe because older workers recover more slowly from am injury. In construction, the injuries caused by a workplace accident were largely and significantly more severe than in the other sectors: injured workers had about $13 \%$ more days of injury recovery than in manufacturing and other sectors. Accidents were more severe in the Center and Southern part of Italy and less severe 
Table 5: OLS estimation results of the injury severity equation

\begin{tabular}{|c|c|c|c|}
\hline Variable & Coeff. & & S.E..$^{\S}$ \\
\hline \multicolumn{4}{|c|}{ Contract type - Reference: Permanent and full-time job } \\
\hline Temporary and full-time job & 0.1374 & $* * *$ & 0.0058 \\
\hline Temporary and part-time job & -0.0164 & $* * *$ & 0.0051 \\
\hline Permanent \& part-time job & -0.0049 & $* *$ & 0.0022 \\
\hline \multicolumn{4}{|c|}{ Worker type - Reference: Standard employee } \\
\hline Apprentice & -0.0521 & $* * *$ & 0.0114 \\
\hline TWA worker & -0.1481 & $* * *$ & 0.0131 \\
\hline Continuous collaborator & -0.0888 & $* * *$ & 0.0121 \\
\hline Female & -0.0388 & $* * *$ & 0.0020 \\
\hline Italian & 0.0539 & $* * *$ & 0.0023 \\
\hline Vehicle involved & 0.1424 & $* * *$ & 0.0033 \\
\hline \multicolumn{4}{|l|}{ Sector-Reference: Manufacturing } \\
\hline Construction & 0.1256 & $* * *$ & 0.0029 \\
\hline Other & -0.0027 & & 0.0020 \\
\hline \multicolumn{4}{|l|}{ Age categories - Reference: $[15,24]$} \\
\hline$[25,34]$ & 0.1193 & $* * *$ & 0.0033 \\
\hline$[35,44]$ & 0.2284 & $* * *$ & 0.0033 \\
\hline$[45,54]$ & 0.3325 & $* * *$ & 0.0033 \\
\hline$[55,64]$ & 0.4317 & $* * *$ & 0.0040 \\
\hline \multicolumn{4}{|c|}{ Geographic location of the establishment-Reference: North-West } \\
\hline North-East & -0.0387 & $* * *$ & 0.0021 \\
\hline Centre & 0.0295 & $* * *$ & 0.0023 \\
\hline South & 0.1414 & $* * *$ & 0.0024 \\
\hline \multicolumn{4}{|l|}{ Year-Reference: 2009} \\
\hline 2010 & 0.0013 & & 0.0023 \\
\hline 2011 & 0.0002 & & 0.0024 \\
\hline 2012 & 0.0034 & & 0.0025 \\
\hline 2013 & 0.0125 & $* * *$ & 0.0026 \\
\hline \multicolumn{4}{|l|}{ Month-Reference: January } \\
\hline February & -0.0184 & $* * *$ & 0.0040 \\
\hline March & -0.0283 & $* * *$ & 0.0039 \\
\hline April & -0.0439 & $* * *$ & 0.0040 \\
\hline May & -0.0507 & $* * *$ & 0.0039 \\
\hline June & -0.0601 & $* * *$ & 0.0039 \\
\hline July & -0.0605 & $* * *$ & 0.0038 \\
\hline August & -0.0443 & $* * *$ & 0.0042 \\
\hline September & -0.0415 & $* * *$ & 0.0039 \\
\hline October & -0.0309 & $* * *$ & 0.0039 \\
\hline November & -0.0205 & $* * *$ & 0.0040 \\
\hline December & 0.0194 & $* * *$ & 0.0042 \\
\hline Constant & 2.6178 & $* * *$ & 0.0050 \\
\hline Number of observations & \multicolumn{3}{|c|}{$1,350,593$} \\
\hline$R^{2}$ & \multicolumn{3}{|c|}{0.0272} \\
\hline
\end{tabular}

Notes: *** Significant at $1 \%$; ** significant at $5 \%$.

$\S$ Standard errors are robust to heteroskedasticity and within-worker correlation. 
in the North-East. Finally, we found that the number of days of injury recovery significantly increased in 2013 by about $1.3 \%$ compared to 2009 .

Table 6 reports the estimated coefficients of the contract type when fixed effects at firm or/and worker level are included in the model specification. Panel a) summarizes the estimation results shown in Table 5 for the type of contract. Panels b) and c) report the results of the models with fixed effects, respectively, at firm level and worker level. Finally, panel d) of Table 6 displays the estimation results when we plugged into Equation (1) both the firm and the worker fixed effects. The inclusion of the fixed effects at different levels did not modify, from the qualitative point of view, the estimated impact of the type of contract on injury severity. Quantitatively, the omission of the fixed effects generated an upward bias on the coefficient associated to the indicator of a temporary job. This means that there was a positive correlation between the unobservables at firm or worker levels determining the injury severity and the likelihood that the contract of the worker involved in the accident was temporary. This is the case if, for instance, firms where the working conditions were more risky for workers' health were those which more easily hired workers on the basis of temporary contracts. At worker level this means that workers who were more likely to hold a temporary contract, like less experienced or with shorter tenure, were individuals who were more likely to experience a more severe accident.

The estimated effects of the indicators for part-time jobs (both permanent and temporary) were also upward biased when the fixed effects were not included among the set of regressors. This means that there was a positive correlation between the probability of having a part-time position and the unobserved determinants of injury severity. This might be due to the fact that firms more oriented to hire part-time workers were firms where the production technology was organized so that workplace accidents resulted in more severe injuries. At the individual level, this implies that workers who preferred to work part-time were also individuals who were less careful on the workplace.

In the model with fixed effects at worker level, the identification of the effect of the contract type hinged on workers who had multiple accidents and who had different types of contract across workplace accidents. This means that identification was based on a small fraction of the whole sample. As a matter of fact, only 19,829 workers had multiple accidents (corresponding to 22,476 records) and varied type of contract. This resulted in much larger standard errors of 
Table 6: Fixed effects estimation results of the injury severity equation

\begin{tabular}{|c|c|c|c|}
\hline Variable & Coeff. & & S.E. \\
\hline \multicolumn{4}{|l|}{ a) Without fixed effects ${ }^{\S}$} \\
\hline \multicolumn{4}{|c|}{ Contract type-Reference: Permanent and full-time job } \\
\hline Temporary \& full-time job & 0.1374 & $* * *$ & 0.0058 \\
\hline Temporary \& part-time job & -0.0164 & $* * *$ & 0.0051 \\
\hline Permanent \& part-time job & -0.0049 & $* *$ & 0.0022 \\
\hline \multicolumn{4}{|l|}{ b) Fixed effects at firm level ${ }^{\dagger}$} \\
\hline \multicolumn{4}{|c|}{ Contract type - Reference: Permanent and full-time job } \\
\hline Temporary \& full-time job & 0.0897 & $* * *$ & 0.0078 \\
\hline Temporary \& part-time job & -0.0559 & $* * *$ & 0.0071 \\
\hline Permanent \& part-time job & -0.0402 & $* * *$ & 0.0032 \\
\hline \multicolumn{4}{|c|}{ c) Fixed effects at worker level ${ }^{\S}$} \\
\hline \multicolumn{4}{|c|}{ Contract type-Reference: Permanent and full-time job } \\
\hline Temporary \& full-time job & 0.0892 & $* * *$ & 0.0180 \\
\hline Temporary \& part-time job & -0.0490 & $* *$ & 0.0214 \\
\hline Permanent \& part-time job & -0.0410 & $* * *$ & 0.0091 \\
\hline \multicolumn{4}{|c|}{ d) Fixed effects at worker and firm level ${ }^{\dagger}$} \\
\hline \multicolumn{4}{|c|}{ Contract type-Reference: Permanent and full-time job } \\
\hline Temporary \& full-time job & 0.1253 & $*$ & 0.0723 \\
\hline Temporary \& part-time job & -0.0641 & & 0.0811 \\
\hline Permanent \& part-time job & -0.0460 & & 0.0323 \\
\hline Number of observations & \multicolumn{3}{|c|}{$1,350,593$} \\
\hline Number of firms & \multicolumn{3}{|c|}{304,258} \\
\hline Number of workers & \multicolumn{3}{|c|}{$1,152,627$} \\
\hline \multicolumn{4}{|c|}{$\begin{array}{l}\text { Notes: *** Significant at } 1 \% ; * * \text { significant at } 5 \% ; * \text { significant at } 10 \% \text {. The estimated coefficients of all the } \\
\text { other regressors are not reported for the sake of brevity. They are available from the authors upon request. } \\
\text { Standard errors are robust to heteroskedasticity and within-firm correlation. } \\
\text { S Standard errors are robust to heteroskedasticity and within-worker correlation. } \\
\ddagger \text { Standard errors are robust to heteroskedasticity and within-firm, within-worker correlation (Cameron et al., 2011). }\end{array}$} \\
\hline
\end{tabular}

the estimated coefficients of the indicator dummies for the contract type when moving from the model without fixed effects to the model with fixed effects at worker level.

Conditional on the worker fixed effects, the firm fixed effects might still be correlated to the contract type. Similarly, conditional on the firm fixed effects, the worker fixed effects might still be correlated to the contract type. Leaving either the firm fixed effects or the worker fixed effects out of the model might result in biased estimates due to an omitted variable problem. Identifying both the firm and the worker fixed effects requires however to have workers that experienced accidents at multiple employers and that changed the type of contract (Abowd et al., 2002). Identification is therefore based on an even smaller number of observations than the case in which only the worker fixed effect was included in the model. Panel d) of Table 6 reports the estimation results of the coefficient of the variables of main interest when both the worker and the firm fixed effects were included in Equation (1). From the quantitative and qualitative viewpoints, they are in line with the estimation results reported in panels b) and c) of Table 6. 


\subsection{Assortative matching}

After the estimation of the equations with fixed effects both at worker and at firm levels, we computed the correlations between the two types of fixed effects, in order to understand whether there was negative or positive assortative matching between workers' and employers' unobserved components of injury severity. In the economic literature (see, e.g., Atakan (2006), and references within), assortative matching occurs when agents sort themselves non-randomly into matches. There is positive assortative matching if workers' and employers' fixed effects are positively correlated, meaning that workers who are very likely to incur in a severe injury match with firms in which severe injuries are more likely to take place. The assortative matching is negative if that correlation is negative. Since we could disentangle the firm fixed effects from the worker fixed effects only for firms displaying workers' mobility, after the benchmark regression we estimated correlations on the basis of only those observations in firms which displayed some workers' mobility. The firms with movers could be divided into different groups of connected firms and workers, such that within a group there was worker mobility and between groups there was no mobility (Cornelissen, 2008). Abowd et al. (2002) showed that within each connected group of firms and workers, it is possible to identify and disentangle the firm fixed effects from the worker fixed effects. This also means that in each group the fixed effect of one firm is normalized to zero. When correlating the worker and the firm effects with each other, it has to be considered that we identify relative firm fixed effects within groups, since in different groups a different normalization is imposed (Cornelissen, 2008).

For this reason, Table 7 displays the average across groups of the correlation between firm and worker fixed effects, weighting each group by the number of observations in that group. As pointed out by Abowd and Kramarz (2004) and Andrews et al. (2008), the estimated correlation between the worker and firm fixed effects might be biased due to low observed workers' mobility across firms. In order to assess the importance of the limited-mobility bias, in Table 7 we also present: i) statistics estimated after selecting firms with different minimum number of movers and workers with different minimum numbers of observations; ii) the bias corrected correlation in the largest group of connected firms and workers estimated as described in Gaure (2014a,b).

The bottom of Table 7 shows that there was a small difference between the uncorrected and 
Table 7: Correlation between worker and firm fixed effects

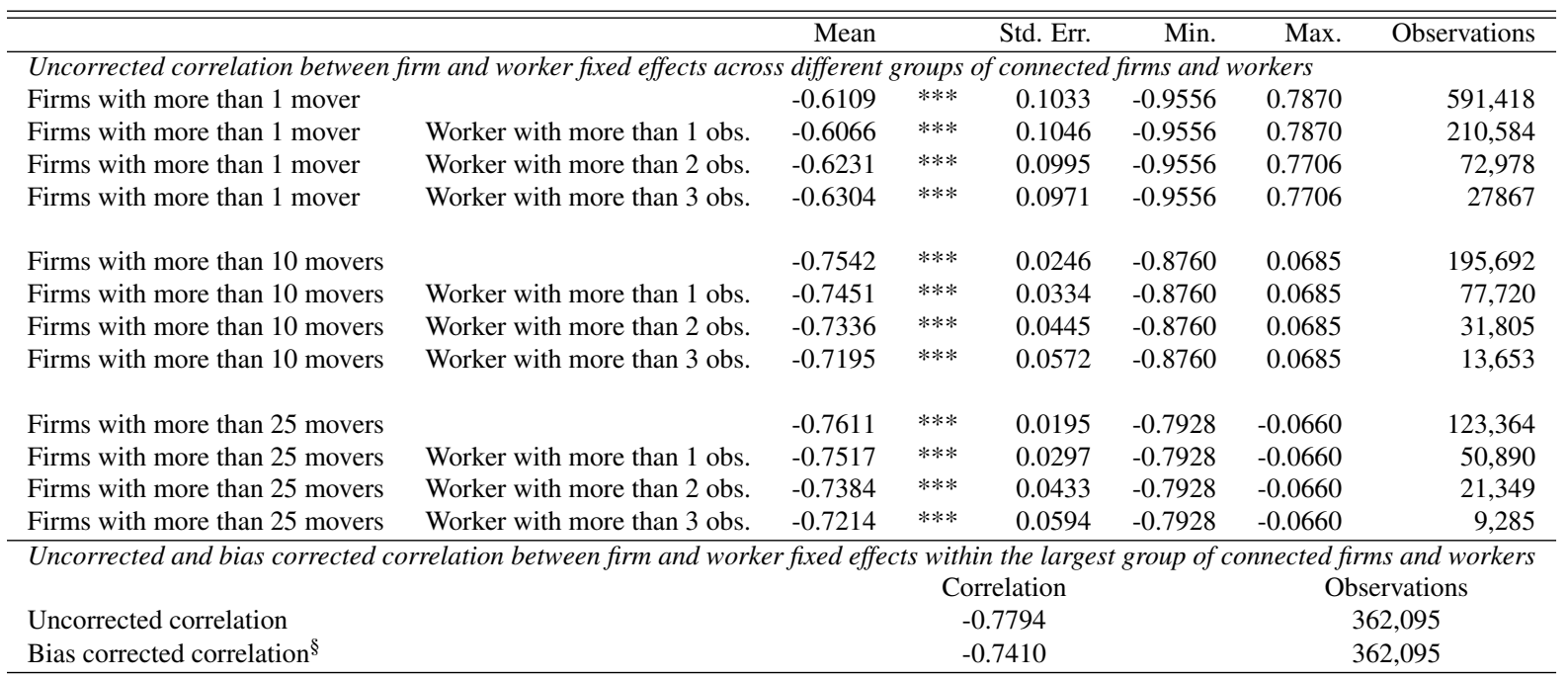

Notes: *** Significant at $1 \%$.

$\S$ The biased corrected correlation is estimated as described in Gaure (2014a,b) and using the R package lfe (Gaure, 2015).

the bias corrected correlation. Moreover, the correlation between the worker and the firm fixed effects was strongly negative. We found therefore evidence consistent with negative assortative matching: conditional on experiencing a workplace accident, workers who were injured more severely worked in less dangerous firms and firms with more dangerous workplaces hired workers who were less prone to dangerous accidents. Thus, it seems that in job matching in Italy there was mutual compensation of unfavorable workplace safety characteristics.

\subsection{Under-reporting}

Table 8 displays the DD estimation results after correcting for under-reporting of temporary workers. Qualitatively, we got estimation results in line with those of the baseline model presented in Table 6 . The positive effect of temporary and part-time contracts on injury severity is however now smaller, although still significantly different from zero. Without controlling for firm fixed effects, we found that temporary full-timers got $6.4 \%$ more days of injury recovery than permanent full-timers. With the inclusion of the firm fixed effects, which returns estimation results robust to omitted firm characteristics, we found that in case of a workplace accident, temporary and full-time workers got $3.4 \%$ more days of injury recovery than permanent and full-time workers. A similar gap between temporary and permanent workers stemmed from 
part-time jobs: conditional on experiencing an accident, the number of days of injury recovery of temporary part-timers were $3.5 \%$ significantly larger than those of permanent part-timers $(-0.0034+0.0386=0.0352)$, and in line with those of permanent and full-time workers. This means that working part-time was associated with less important injuries, but within the group of part-timers, working on a temporary basis generated more severe injuries with the same intensity as within the group of full-timers.

The correction for under-reporting on the basis of accidents in commuting suggested that: i) the effect of temporary jobs on the severity of a workplace accident was overestimated if under-reporting was not taken into account; ii) temporary workers systematically underreported workplace accidents.

Table 8: DD estimation results exploiting commuting accidents

\begin{tabular}{|c|c|c|c|}
\hline Variable & Coeff. & & S.E. \\
\hline \multicolumn{4}{|l|}{ a) Without fixed effects ${ }^{\S}$} \\
\hline \multicolumn{4}{|c|}{ Contract type-Reference: Permanent and full-time job } \\
\hline Temporary \& full-time job & 0.0616 & **** & 0.0135 \\
\hline Temporary \& part-time job & -0.0326 & $* * *$ & 0.0110 \\
\hline Permanent \& part-time job & -0.0257 & $* * *$ & 0.0051 \\
\hline \multicolumn{4}{|l|}{ b) Fixed effects at firm level ${ }^{\dagger}$} \\
\hline \multicolumn{4}{|c|}{ Contract type-Reference: Permanent and full-time job } \\
\hline Temporary \& full-time job & 0.0339 & ** & 0.0165 \\
\hline Temporary \& part-time job & -0.0034 & & 0.0144 \\
\hline Permanent \& part-time job & -0.0386 & **** & 0.0073 \\
\hline \# of observations & \multicolumn{3}{|c|}{$1,630,478$} \\
\hline \# of firms & \multicolumn{3}{|c|}{349,559} \\
\hline \# of workers & \multicolumn{3}{|c|}{$1,389,663$} \\
\hline
\end{tabular}

Notes: *** Significant at $1 \%$; ** significant at $5 \%$. The estimated coefficients of all the other regressors are not reported for the sake of brevity. They are available from the authors upon request.

$\S$ Standard errors are robust to heteroskedasticity and within-worker correlation.

${ }^{\dagger}$ Standard errors are robust to heteroskedasticity and within-firm correlation.

\section{Discussion}

In our analysis of Italian micro data our main findings were that: i) workers with a temporary contract, if subject to a workplace accident, were more likely to be confronted with more severe injuries than permanent workers; ii) although for part-time workers injuries severity were less severe than for full-time workers, the gap between permanent and temporary workers was detected both among part-timers and among full-timers; iii) not taking into account injury under-reporting of temporary workers resulted in an upward bias in the estimation of the impact of temporary work on injury severity. 
The mechanisms explaining our empirical findings are not obvious. A potential explanation is job tenure which is related both to workplace safety behavior and to type of contract. More experienced workers are less likely to undertake unforeseen dangerous actions, while at the same time more experienced workers are more likely to have stepped to open-ended arrangements. Unfortunately, the INAIL dataset did not contain information on job tenure or variables to proxy it. Therefore, it was not possible to distinguish between the effect of job seniority and the effect of having a temporary contract. It was not clear as well whether differences in investment in workplace safety training contributed to the differences in severity of workplace accidents. It could be that employers invested more in workplace safety training of workers in permanent jobs than they did in workers in temporary jobs.

Since the inclusion of firm fixed effects did not influence the relationship between temporary contract and the injury severity of the workplace accident, the type of firm did not seem to be the intermediate variable. This however did not exclude the possibility that, within firms, the nature of the work could vary between different categories of workers. For example, temporary workers might be more likely, ceteris paribus, to be assigned by the employer to dangerous tasks because they might have less bargaining power.

Sometimes, it is difficult to draw conclusions about the determinants of workplace safety because of reporting behavior. It may be the case that workers on temporary jobs are less likely to report a workplace accident in fear that their contract will not be extended. To investigate the influence of reporting behavior, we exploited a difference-in-differences analysis using information on commuting accidents as a counterfactual. We found that the effect on the severity of a workplace accident of having a temporary job instead of a permanent job was reduced but was still significantly different from zero. This suggested that under-reporting of small workplace accidents by temporary workers was not a marginal issue in Italy.

Finally, our data allowed us to study whether there was assortative matching between workers and firms along the dimension of workplace safety, i.e. whether workers who experienced a more severe workplace accident were less likely or more likely to match with firms which experienced more severe workplace accidents. We found strong negative correlation between worker fixed effects and firm fixed effects consistent with negative assortative matching. Firms with a more dangerous workplace hired workers who were less prone to severe accidents. 


\subsection{Practical implications}

From our findings we derive two main practical implications. First, since we found that temporary workers were more likely to experience severe injuries once a workplace accident took place, public policy should aim at improving workplace safer for temporary workers. However, designing effective interventions in reaching this goal requires identification of the factors determining the positive relation between having a temporary position and experiencing more severe injuries when a workplace accident occurs. If the key explanation is temporary workers having lower job seniority and, thereby, lower familiarity with the job that is needed to avoid work injury, then policy intervention should aim to make it easier for temporary workers to receive training on site-specific accident prevention. To achieve this, workplace safety procedures should be included in the contract. If instead the positive relation originates from temporary workers being in a weak position to challenge the employer when assigned to hazardous tasks, reducing the duality between temporary and permanent jobs which characterizes the Italian labor market could be a sensible intervention to realign the gap. The 2015 reform of the Italian labor market (Legislative Decree No. 23/2015) partially followed this direction by significantly lowering the firing costs of new open-ended contracts.

Second, the evidence of temporary workers under-reporting workplace accidents has important implications for public policy. Under-reporting undermines not only the validity of statistical analysis with accident data, but it is also a key starting point to ensure that temporary workers will have a safe workplace. In fact, if employers are aware that temporary workers are not willing to report workplace accidents because of their precariousness, employers may use temporary jobs as a way to avoid meeting all the obligations dictated by workplace safety laws. More stringent regulations and penalties for employers not reporting workplace accidents, more inspections to collect information on employers' work-site safety practices and awareness campaigns urging temporary workers to be proactive about their own safety could be devices to improve workplace safety.

\subsection{Limitations and future directions}

Mainly due to limitations imposed by the data, our study left some ground for future research. First, as mentioned before, our policy advice is conditional on the key mechanisms driving our 
findings, which we were not able to isolate in our study. The INAIL dataset lacks information on the labor market history of the worker, i.e. on work experience and job tenure in the firm the accident took place. This prevented us from distinguishing the effect of specific knowledge and familiarity with the specific workplace from the employers' decision to allocate temporary workers to hazardous tasks. Second, the INAIL dataset contains only information on work related accidents. It does not have information on workers in the same firm who did not experience an accident. Therefore, we were not able to model workplace accident incidence rates. We had to limit our study to the analysis of the determinants of injury severity conditional on experiencing a workplace accident.

Further research to identify specific mechanisms through which temporary workers suffer more severe injuries and further research to analyze differentials in workplace accident incidence rates requires the matching of the INAIL dataset with administrative data on jobs, like the Work Histories on Panel Data extracted by the archives of the National Social Security Institute (INPS). To establish the relationship between workplace safety and nature of the contract in more detail it would be helpful to study the contents of the worker contracts concerning for example the inclusion of workplace safety procedures and job training with a workplace safety component. For a thorough analysis of the differences in the severity of workplace accidents between temporary workers and permanent workers it would also be helpful to have information of the pre-employment health condition of the temporary worker as compared to the permanent worker.

\section{References}

Abadie, A. (2005). Semiparametric difference-in-differences estimators. Review of Economic Studies $72,1-19$.

Abowd, J., R. Creecy, and F. Kramarz (2002). Computing person and firm effects using linked longitudinal employer-employee data. Longitudinal Employer-Household Dynamics Technical Papers 2002-06, Center for Economic Studies, U.S. Census Bureau,.

Abowd, J. and F. Kramarz (2004). Are good workers employed by good firms? A simple test of positive assortative matching models. Econometric Society 2004 North American Winter Meetings 385, Econometric Society.

Amuedo-Dorantes, C. (2002). Work safety in the context of temporary employment: The Spanish experience. Industrial and Labor Relations Review 55(2), 262-272. 
Andrews, M., L. Gill, T. Schank, and R. Upward (2008). High wage workers and low wage firms: Negative assortative matching or limited mobility bias? Journal of the Royal Statistical Society Series A 171(3), 673-697.

Atakan, A. (2006). Assortative matching with explicit search costs. Econometrica 74(3), 667-680.

Bena, A., M. Giraudo, R. Leombruni, and G. Costa (2013). Job tenure and work injuries: A multivariate analysis of the relation with previous experience and differences by age. BMC Public Health 13:869, $1-9$.

Boone, J. and J. C. van Ours (2006). Are recessions good for workplace safety? Journal of Health Economics 25(6), 1069-1093.

Boone, J., J. C. van Ours, J. P. Wuellrich, and J. Zweimüller (2011). Recessions are bad for workplace safety. Journal of Health Economics 30(4), 764-773.

Cameron, A., J. Gelbach, and D. Miller (2011). Robust inference with multiway clustering. Journal of Business \& Economic Statistics 29(2), 238-249.

Cornelissen, T. (2008). The Stata command felsdvreg to fit a linear model with two high-dimensional fixed effects. Stata Journal 8(2), 170-189.

Davies, R., P. Jones, and I. Nunez (2009). The impact of the business cycle on occupational injuries in the UK. Social Science and Medicine 69(2), 178-182.

Dembe, A., J. Erickson, R. Delbos, and S. Banks (2006). The impact of overtime and long work hours on occupational injuries and illnesses: New evidence from the Unites States. Occupational \& Environmental Medicine 62(9), 588-597.

Eurostat (2014). Key figures on Europe; Pocketbooks 2014 edition. European Union.

Galizzi, M., P. Miesmaa, L. Punnett, C. Slatin, and The Phase in Healthcare Research Team (2010). Injured workers' underreporting in the health care industry: An analysis using quantitative, qualitative, and observational data. Industrial Relations 49(1), 22-43.

García-Serrano, C., V. Hernanz, and L. Toharia (2010). Mind the gap, please! The effect of temporary help agencies on the consequences of work accidents. Journal of Labor Research 31(2), 162-182.

Gaure, S. (2014a). Correlation bias correction in two-way fixed-effects linear regression. Stat 3(1), 379-390.

Gaure, S. (2014b). lfe: Linear group fixed effects. $R$ Journal 5(2), 104-117.

Gaure, S. (2015). lfe: Linear group fixed effects. R package version 2.4, URL: http://CRAN.Rproject.org/package=lfe.

Guadalupe, M. (2003). The hidden costs of fixed term contracts: The impact on work accidents. Labour Economics 10(3), 339-357.

Pouliakas, K. and I. Theodossiou (2013). The economics of health and safety at work: An interdisciplinary review of the theory and policy. Journal of Economic Surveys 27(1), 167-208.

Probst, T. M., C. Barbaranelli, and L. Petitta (2013). The relationship between job insecurity and accident under-reporting: A test in two countries. Work \& Stress 27(4), 383-402. 
Rosenman, K. D., A. Kalush, M. J. Reilly, J. C. Gardiner, M. Reeves, and Z. Luo (2006). How much work-related injury and illness is missed by the current national surveillance system? Journal of Occupational and Environmental Medicine 48(4), 357-365.

Shannon, H. S. and G. S. Lowe (2002). How many injured workers do not file claims for workers' compensation benefits? American Journal of Industrial Medicine 42(6), 467-473.

Tucker, S., D. Diekrager, N. Turner, and E. K. Kelloway (2014). Work-related injury underreporting among young workers: Prevalence, gender differences, and explanations for underreporting. Journal of Safety Research 50(1), 67-73. 